\title{
The demand for health insurance and behavioural economics
}

\author{
K. P. M. van Winssen ${ }^{1}$ - R. C. van Kleef ${ }^{1}$ - W. P. M. M. van de Ven ${ }^{1}$
}

Published online: 29 February 2016

(C) Springer-Verlag Berlin Heidelberg 2016

\section{Discrepancy between insurance theory and the Dutch supplementary insurance}

A vast amount of traditional economic literature [e.g. 2, 13, 20] describes the advantages and disadvantages of taking out health insurance. The major advantage of insurance is the reduction of uncertainty regarding financial losses [12]. The welfare gain from this uncertainty reduction depends on the individual's degree of risk aversion [14], which is affected by the presence of background risks (i.e. risks that cannot be avoided or insured against, such as labour income risks). Several studies show that background risks to wealth makes risk averse individuals behave in a more risk averse way with respect to any other independent risk [e.g. 5]. This concept is called risk vulnerability [8], and causes insured to reduce their exposure to avoidable risks, for instance by increasing their insurance demand [9]. Another advantage of health insurance is that it provides access to healthcare services that would otherwise be unaffordable [12]. The disadvantages of insurance are moral hazard, the loading fee and the transaction costs related to purchasing the insurance and handling the claims. The literature shows that full insurance is far from optimal and that a mix between coverage and cost sharing is preferred. Optimal designs of health insurance (1) protect individuals against unpredictable high financial risks, (2) provide access to otherwise unaffordable healthcare services, (3) include first-dollar cost sharing, and (4) incorporate

K. P. M. van Winssen

vanwinssen@bmg.eur.nl

$\triangle$ W. P. M. M. van de Ven vandeven@bmg.eur.nl

1 Institute of Health Policy and Management, Erasmus University Rotterdam, Rotterdam, The Netherlands individual caps on out-of-pocket expenses [4] (see Table 1). In practice, however, insurance design does not always comply with these principles. An obvious example concerns the Dutch supplementary health insurance (SHI). As we will explain below, the Dutch SHI substantially deviates from the optimal design. It is therefore surprising to observe the popularity of this scheme: $84 \%$ of the Dutch insured took out SHI in 2015. This intriguing paradox suggests that additional aspects-compared to those mentioned in the traditional economic literature - may play a role in the demand for health insurance. After a short description of the Dutch SHI, we will discuss a series of potential explanations for the high uptake of "suboptimal" insurance stemming from key insights described in the behavioural economic literature.

Dutch insured can buy a SHI for healthcare services not (or partially) covered by mandatory basic health insurance (BHI), such as dental care, physiotherapy, durable medical equipment, alternative medicines, pharmaceuticals, care consumed in a foreign country, orthodontics and maternity care. The Dutch SHI market is a free market, which means that insurers are free to determine the premiums, coverage and cost sharing arrangements. The risk reduction resulting from the Dutch SHI is limited because most healthcare services covered do not involve large losses, and because coverage limits are applied (see Table 1). The latter implies that, after the limit is reached, all expenses have to be paid out-of-pocket by the insured, which-in case of care consumed in a foreign country or dental care after an accident, for example - could lead to substantial out-ofpocket expenses. Next to the limited risk reduction, the Dutch SHI mostly provides access to already affordable healthcare services such as dental check-ups and regular consultations with the physiotherapist. These characteristics suggest that the consumers' welfare gain from Dutch SHI may be limited. At the same time the consumers' 
Table 1 Characteristics of health insurance design: "optimal" versus the Dutch supplementary health insurance (SHI)

\begin{tabular}{|c|c|c|c|}
\hline \multicolumn{2}{|c|}{ Characteristic } & \multirow{2}{*}{$\begin{array}{l}\text { Optimal insurance design } \\
\text { Unpredictable high financial risks } \\
\text { and otherwise unaffordable } \\
\text { healthcare services }\end{array}$} & \multirow{2}{*}{$\begin{array}{l}\text { Dutch SHI } \\
\text { Mostly predictable low financial risks (e.g. dental check-ups } \\
\text { and consultations at the physiotherapist). Some SHIs } \\
\text { provide protection against large expenses, but these are } \\
\text { mostly maximised (e.g. dental expenses after an accident } \\
\text { (up to about } € 10,000) \text {, care consumed in a foreign country) }\end{array}$} \\
\hline 1 & $\begin{array}{l}\text { What does the insurance provide } \\
\text { protection against and what does it } \\
\text { provide access to? }\end{array}$ & & \\
\hline 2 & Is cost sharing applied and if so, how? & $\begin{array}{l}\text { Yes, in the form of first-dollar cost } \\
\text { sharing }\end{array}$ & $\begin{array}{l}\text { No, except only dental insurances apply coinsurance of } \\
20-25 \%\end{array}$ \\
\hline 3 & $\begin{array}{l}\text { Are caps on out-of-pocket expenses } \\
\text { applied and if so, how? }\end{array}$ & $\begin{array}{l}\text { Yes, in the form of an individual } \\
\text { cap }\end{array}$ & $\begin{array}{l}\text { No, after the coverage limits (e.g. nine treatments at a } \\
\text { physiotherapist) are reached, insured pay the full expenses } \\
\text { for healthcare services out-of-pocket }\end{array}$ \\
\hline
\end{tabular}

welfare loss may be substantial due to the loading fee (about $17 \%$ of the premium), moral hazard, and transaction costs. Substantial moral hazard can be expected, because most healthcare services are subject to first-dollar coverage, while substantial transaction costs could arise since many insurers offer many different SHI policies, making the choice of SHI time consuming.

In sum, the discrepancies in Table 1 show that the design of the Dutch SHI is opposite to what the traditional economic theory on optimal insurance design would predict. Nevertheless, all Dutch insurers offer these kinds of SHI policies, and many Dutch insured actually take out one or more of these SHI policies. An explanation of the high uptake of the Dutch SHI could be that Dutch insured are extremely risk averse, implying that the consumer welfare gain from risk reduction could still outweigh the substantial welfare loss from moral hazard, the loading fee and transaction costs. If this were true, however, one would expect (much) higher coverage limits than applied in the Dutch SHI, since the gains from financial risk reduction would then be even larger than under the current design. Furthermore, an increase in risk aversion due to background risk could explain the high uptake of the SHI. However, we consider it highly unlikely that there is substantial background risk that could have affected the demand for SHI in the last decade for over $84 \%$ of the Dutch individuals. After all, the Dutch have significant social security such as child allowances, social welfare payments, comprehensive social health insurance, disability insurance and state pensions. In this editorial we will discuss two alternative explanations for the high uptake of "suboptimal" insurance.

\section{Behavioural economics}

Key insights from behavioural economics may help explain the demand for health insurance. We provide two potential explanations: (1) other key aspects stemming from behavioural economics other than risk reduction, and access to otherwise unaffordable healthcare services provide a welfare gain to individuals when taking out SHI; and/or (2) insured make suboptimal choices.

\section{Potential aspects that provide a welfare gain from taking out SHI}

\section{Loss aversion}

A first potential aspect that may provide a welfare gain to insured when taking out SHI is loss aversion, which is a key insight from the 'cumulative prospect theory' developed by Tversky and Kahneman [18]. Loss aversion regards the phenomenon that 'losses loom larger than gains' and that 'the aggravation that one experiences in losing a sum of money appears to be greater than the pleasure associated with gaining the same amount' [11]. Research concerning loss aversion and insurance decisions has been done in the past [e.g. 10, 16], but not regarding SHI. Loss aversion plays a role only in mixed prospects (i.e. where the outcome of a prospect is either a gain or a loss). In such mixed prospects, the presence of loss aversion depends upon the individuals' reference point: prospects coded as losses from this reference point are affected by loss aversion. It is often assumed that the current state of wealth is the reference point in any decision. Subsequently, the taken reference point concerning the decision to take out SHI (i.e. either SHI or no SHI) is essential to the effect of loss aversion. When taking out SHI (especially via the internet), Dutch insurers guide individuals through the different choices they have to make: which BHI, which deductible level and which SHI to apply for. With respect to the choice of the SHI, some insurers attach virtual labels to one of the offered policies stating 'most commonly chosen (in your situation)', nudging insured to take out SHI by carefully setting the default option. Next to the fact that most insured already had SHI in the previous year (i.e. their current state of wealth), this might additionally provide individuals with a reference point equal to having a SHI. From this reference point, an aversion to potential out-ofpocket expenses for healthcare services not covered by SHI 
(i.e. in case of not taking out SHI) could be created and a preference for the status quo (i.e. having SHI) could arise. This would imply that in the presence of loss aversion, the welfare gain from taking out SHI would be higher than in the absence of loss aversion.

\section{Ambiguity aversion}

A second potential aspect that may provide a welfare gain from taking out SHI is ambiguity aversion (sometimes also referred to as uncertainty aversion). Ambiguity aversion captures individuals' preference for prospects with known probabilities over prospects with unknown probabilities and was first presented by Ellsberg [6]. In a hypothetical experiment, individuals were confronted with two urns. The first urn contained 100 red and black balls in an unknown ratio and the second urn contained exactly 50 red and 50 black balls. The majority of respondents preferred to bet on either red or black in urn two rather than in urn one, although the expected outcome for both urns was the same, indicating ambiguity aversion. Missing information that is relevant and could be known creates the uncertainty about probabilities. From ambiguity aversion it then follows that individuals will value provision of any information that reduces their ambiguity, even if it will not change their decision, while standard economic theory predicts that the demand for information depends on its value in making decisions. When deciding to take out SHI, ambiguity aversion might create a preference for taking out SHI. This is caused by the fact that uncertainty (or ambiguity) is present regarding the choice option of not taking out SHI. After all, insured do not know (and are bad at estimating) their probability that healthcare expenses occur that could have been covered by SHI. With SHI this type of ambiguity is absent and could therefore provide a welfare gain.

\section{Liquidity constraints}

Liquidity constraints are a third potential aspect that may provide a welfare gain from taking out SHI to insured. Liquidity constraints imply that individuals do not have the financial possibilities to free up an (substantial) amount of money at some point in time. For instance, if individuals do not take out SHI, but unexpectedly need several treatments from a healthcare provider that are not covered by BHI, they might not be able to pay the bill they receive. This might be due to the fact that they are financially illiquid. Since this situation could be prevented, at least for healthcare services that are covered by SHI, individuals might be more inclined to take out SHI. Of course, individuals then have to pay a (additional) monthly premium but they prevent the unpleasant situation where they cannot pay a large bill (or even forego care) due to liquidity constraints. This would imply that in the presence of liquidity aversion, the welfare gain from taking out SHI would be higher than in the absence of liquidity aversion.

\section{Debt aversion}

A fourth potential aspect that may provide a welfare gain from taking out SHI is debt aversion. Debt aversion stems from mental accounting theory [17] and is shown by individuals' preference to prepay for consumption and to get paid for work after completion. Essentially, individuals dislike the feeling of 'having the meter running'. A phenomenon called the flat rate bias indicates that individuals prefer flat-rate pricing schemes even if they pay more for the same usage. Debt aversion is explained by two motives: (1) individuals hope to enjoy the product or service untroubled from payment concerns, and (2) individuals want to avoid the unpleasant experience of paying for consumption that has been enjoyed already. So, debt aversion predicts that insured prefer flat-rate pricing schemes (e.g. BHI or SHI), and dislike paying for healthcare after consumption. After all, with SHI, healthcare services (up to a maximum) do not have to be paid after usage, but are prepaid through a monthly flat rate. Without SHI, the individual receives the bill after usage of the healthcare service, which is not preferred as a result of debt aversion. This would imply that, in the presence of debt aversion, the welfare gain from taking out SHI would be higher than in the absence of debt aversion.

\section{Making a suboptimal choice}

An alternative explanation for the high uptake of SHI in the Netherlands is that a large number of insured make suboptimal choices due to several behavioural economic aspects, meaning that individuals take out SHI while theoretically not taking out SHI would be 'optimal'.,

\footnotetext{
${ }^{1}$ Note that, if insured want coverage for healthcare services not covered by BHI, their only option is the current SHI since no better alternative SHI policies are offered at the Dutch SHI market. One could question why insurers do not offer alternative SHI policies that are more in line with traditional economics. Firstly, this might be due to the fact that other aspects provide a welfare gain to individuals that may affect the decision to take out SHI. Consequently, there might be no need (and no demand) for alternative policies. Secondly, such alternative policies would imply a tendency towards equivalence (i.e. risk rating and risk selection) at the SHI market. However, Dutch society demands solidarity even for healthcare services offered at the free SHI market. A potential fear of reputation loss might therefore prevent insurers from offering such policies.

2 Note that not all insured make a suboptimal choice when taking out SHI. Some insured may buy SHI because they know they will financially profit from it. Nonetheless, $30 \%$ of the Dutch insured with SHI did not file any bills to their insurer for reimbursement in 2013.
} 


\section{Limited knowledge}

A first potential aspect that could indicate why insured make a suboptimal choice when taking out SHI may be individuals' limited knowledge regarding SHI policies. After all, insured are known to have limited knowledge about their health insurance [15] and to misunderstand complex price schedules including premiums and cost sharing arrangements [3]. Dutch individuals, for instance, do not know what type of health policy they have and are ignorant with respect to aspects such as deductibles, coverage and healthcare providers covered. There are two reasons why it could be expected that limited knowledge indeed affects the insured's decision regarding SHI. Firstly, it could be expected that insured do not (exactly) know what they insure against by taking out SHI. Insured could, for instance, not know which benefits are covered and which coverage limits and cost sharing arrangements apply. They might feel like they insure unpredictable and large potential losses, but might be unaware that they are (also) insuring regular dental check-ups. Secondly, it could be expected that insured do not know the costs of healthcare services that are (not) covered by insurance. This makes it hard for insured to make their own trade-off between the premium for SHI and the healthcare services covered by SHI, potentially causing them to make a suboptimal choice. Additionally, making this trade-off might be complex and might impose a high cognitive burden. This could especially be the case for individuals with low levels of numeracy and/or health literacy.

\section{Social comparison}

A second potential aspect that could explain why insured take out SHI regards social comparison [7], where imitation is the most frequent form of peer effect. A norm to conform to the peer (e.g. family and friends) may explain why peer choices, and thus social comparison, indeed matters. Individuals reflect upon what their peers decide and might think 'if my peers are purchasing insurance, I should purchase insurance for myself as well'. The behaviour of peers might potentially affect the decision to take out SHI as well: 'if many of my friends and family take out SHI, I will do too, but if almost nobody takes out insurance, I am also not going to take out SHI'. As long as many insured take out SHI, social comparison could potentially explain why many insured take out SHI.

\section{Decision avoidance}

Decision avoidance is a third potential aspect that could indicate why insured make a suboptimal choice concerning their SHI. Decision avoidance implies a tendency to avoid making a choice by postponing it or by seeking an easy way out that involves no action or no change [1]. Several underlying factors could contribute to decision avoidance. Firstly, a reluctance to take action to change the current state (i.e. omission bias) could result in decision avoidance. Due to this omission bias, insured may automatically renew their current health insurance policy, which mostly includes a SHI. A second underlying factor regards choice and information overload. Research in both economics and psychology questions whether more choice is always in the consumer's interest. Particularly when choice involves health and money-both part of the decision to take out SHI-consumers facing many choices may revert to the status quo even if superior options are available. With respect to the Dutch SHI, many different insurers offer many different types of insurances, with different benefit packages, for different premiums, with different cost sharing arrangements and reimbursement maximums. This could cause the individual to be overwhelmed by too much choice and subsequently make the insured defer the choice and eventually not make any decision at all. A third underlying factor of decision avoidance regards search and transaction costs. Consumer search is costly and a rational consumer will search until the cost of additional searching outweighs its expected benefits. Transaction and search costs, with respect to the SHI, regard the time and effort it takes for an individual to determine whether or not to take out SHI and, if so, which SHI to take out. Search and transaction costs might be very high since insured have many decisions and trade-offs to make regarding their SHI. This could, again, cause insured to automatically renew their current health insurance policy. A fourth underlying factor of decision avoidance regards regret avoidance, which implies that whenever choice can induce regret, individuals have a tendency to eliminate the choice. Regret avoidance helps explain individuals' preference for firstdollar coverage, since many individuals find decisions that involve a trade-off between healthcare and money unpleasant. Consequently, insured (again) might take out SHI, because they may regret not taking out SHI if healthcare expenses do occur and have to be paid for outof-pocket while it would, in retrospect, have been financially profitable to take out SHI. In sum, decision avoidance could cause insured to make suboptimal choices regarding their SHI.

\section{Further research}

It should be emphasised that the behavioural economic aspects presented in this editorial are potential explanations for the observed behaviour. Further (empirical) research is needed to determine whether, and to what extent, the 
potential extensions to the theory on optimal insurance design, and the ideas on consumer choice, hold true in practice. We see at least five directions for further research. Firstly, research could be performed regarding the question whether insured with an insurance policy in the current year indeed are more inclined to take out insurance in the next year (correcting for health status and other background characteristics such as gender, age and social economic status). In this way, the potential effect of loss aversion and decision avoidance on the demand for insurance could be tested. Secondly, research could study the effect of providing insight into the probability of using healthcare services covered by health insurance on the decision to take out insurance, such as that done by Wakker et al. [19]. Such a study could look into the aspects of ambiguity aversion, limited knowledge and social comparison. Thirdly, it could be interesting to perform a discrete choice experiment with respect to design aspects of health insurance, to see which aspects insured value most and what an optimal insurance design would look like to them. Fourthly, research could study the effect of provision of information about health insurance (i.e. what does it cover, what cost sharing arrangements apply, etc.) on the decision to take out insurance. This could provide insights regarding the direct effect of information on the demand for insurance. Fifthly, it would be important to study how the different research areas presented in this editorial (i.e. traditional economics versus behavioural economics) relate to each other. For instance, Gollier and Pratt [8] show that adding a background risk to an individual's initial wealth makes him desire a certain lottery, which he disliked before the background risk was added. This seems quite similar to what Kahneman and Tversky [11] present in their paper when they add a 1000 to an individual's initial wealth and show that the answer to the same lottery reverses. Both these results may relate to an individual's reference point when making (insurance) decisions, and could provide a better understanding of insurance demand. The mentioned directions for further research could contribute to better insurance designs and could help facilitate the insured's decision-making process.

\section{References}

1. Anderson, C.J.: The psychology of doing nothing: forms of decision avoidance result from reason and emotion. Psychol. Bull. 129(1), 139-167 (2003). doi:10.1037/0033-2909.129.1.139
2. Arrow, K.J.: Welfare analysis of change in health co-insurance rates. In: Rosett, R. (ed.) The role of health insurance in the health services sector, pp. 3-23. NBER, New York (1976)

3. Baicker, K., Congdon, W.J., Mullainathan, S.: Health insurance coverage and take-up: lessons from behavioral economics. Milbank Q. 90(1), 107-134 (2012). doi:10.1111/j.1468-0009.2011. 00656.x

4. Buchanan, J.L., Keeler, E.B., Rolph, J.E., Holmer, M.R.: Simulating health expenditures under alternative insurance plans. Manag. Sci. 37(9), 1067-1090 (1991). doi:10.1287/mnsc.37.9. 1067

5. Eeckhoudt, L., Gollier, C., Schlesinger, H.: Changes in background risk and risk taking behavior. Econometrica 64(3), 683-689 (1996). doi:10.2307/2171866

6. Ellsberg, D.: Risk, ambiguity, and the savage axioms. Q. J. Econ. 75(4), 643-669 (1961)

7. Friedl, A., de Miranda, K.L., Schmidt, U.: Insurance demand and social comparison: an experimental analysis. J. Risk Uncertain. 48(2), 97-109 (2014). doi:10.1007/s11166-014-9189-9

8. Gollier, C., Pratt, J.W.: Risk vulnerability and the tempering effect of background risk. Econometrica 64(5), 1109-1123 (1996). doi:10.2307/2171958

9. Guiso, L., Paiella, M.: Risk aversion, wealth, and background risk. J. Eur. Econ. Assoc. 6(6), 1109-1150 (2008). doi:10.1162/ JEEA.2008.6.6.1109

10. Johnson, E.J., Hershey, J., Meszaros, J., Kunreuther, H.: Framing, probability distortions, and insurance decisions. J. Risk Uncertain. 7, 35-51 (1993)

11. Kahneman, D., Tversky, A.: Prospect theory: an analysis of decision under risk. Econometrica 47(2), 263-291 (1979)

12. Nyman, J.A.: The value of health insurance: the access motive. J. Health Econ. 18(2), 141-152 (1999). doi:10.1016/S01676296(98)00049-6

13. Manning, W.G., Marquis, M.S.: Health insurance: the tradeoff between risk pooling and moral hazard. J. Health Econ. 15, 609-639 (1996). doi:10.1016/S0167-6296(96)00497-3

14. Pratt, J.W.: Risk aversion in the small and in the large. Econometrica 32, 122-136 (1964)

15. Reed, M., Fung, V., Price, M., Brand, R., Benedetti, N., Derose, S.F., Newhouse, J.P., Hsu, J.: High-deductible health insurance plans: efforts to sharpen a blunt instrument. Health Aff. 28(4), 1145-1154 (2009). doi:10.1377/hlthaff.28.4.1145

16. Rice, T.: The behavioural economics of health and health care. Annu. Rev. Public Health 34, 431-447 (2013). doi:10.1146/ annurev-publhealth-031912-114353

17. Thaler, R.H.: Mental accounting matters. J. Behav. Decis. Mak. 12(3), 183-206 (1999)

18. Tversky, A., Kahneman, D.: Advances in prospect theory: cumulative representation of uncertainty. J. Risk Uncertain. 5(4), 297-323 (1992). doi:10.1007/BF00122574

19. Wakker, P.P., Timmermans, D.R.M., Machielse, I.: The effects of statistical information on risk and ambiguity attitudes, and on rational insurance decisions. Manag. Sci. 53(11), 1770-1784 (2007). doi:10.1287/mnsc.1070.0735

20. Zeckhauser, R.: Medical insurance: a case study of the tradeoff between risk spreading and appropriate incentives. J. Econ. Theory 2(1), 10-26 (1970). doi:10.1016/0022-0531(70)90010-4 